\title{
The Application of MBTI to Develop A Learning Program: A Case Study for the Personality Type of the Occupational Health and Safety Students
}

\author{
Dr .Nopagon Usahanunth \\ OHS\&E Lecturer, Faculty of Public Health, \\ Western University, Karnchanaburi, Thailand.
}

\begin{abstract}
The application of The Myers-Briggs Type Indicator (MBTI) to develop a learning program as a case study of the personality test for Occupational Health and Safety students to establish a learning program for Occupational Health and Safety professional work. The study results found that personality types of Occupational Health and Safety students shown that the highest models were ISFJ (Introverts, Sensing, Feeling, and Judgment) at $22 \%$ and ISFP (Introverts, Sensing, Feeling, and Perception) at $16 \%$ respectively. These personality types reflect the work of Occupational Health and Safety students in future careers, including responsibility for duty and the importance of attitudes to follow the Occupational Health and Safety law or regulation. The principal learning programs needed to develop their potential are efficient communication, Leadership, and Occupational Health and Safety management.
\end{abstract}

Keywords-MBTI, Personality, OHS professional requirements

\section{INTRODUCTION}

In Thailand, The Occupational Health and Safety students who study in the university under the Department of Labor Protection and Welfare list (OHS students) after graduate will automatically become professional Occupational Health and Safety (OHS officers). Their general duty is to look after all safety and health of workers in the workplace. Accordingly, to maintain the health of all workers equally in various establishments, including evaluating the work environment to be a safe place always to achieve the highest working efficiency that shall not hurt or affect the physical and mental health of other workers as well.

OHS officers who succeed in his career shall demonstrate perseverance and love for the profession that is particularly incumbent in skills, technical knowledge, ethics upheld. As well as interpersonal communication with individuals and other entities. The personality study of Occupational Health and Safety students (OHS students) to aware of themselves for future professional development to meet their future careers. This study can utilize guidance for planning to comply with professional requirements. The OHS officers work under Thai OHS regulation [1] and conduct workers in safe operation. The studying tools were developed from the previous studying the engineer's personality test.[2],[3],[4]

\section{LITERATURE REVIEW}

This paper aims to survey the trend of personalities of OHS students and to know the MBTI personality model in the practice of Occupational Health and Safety professional for the future development of their competency to meet the OHS of expert recommendations.

Jung developed a new condensed form (Short Version Survey) questionnaire of 32 questions and using multiple choice answers 5 Options and attitude in practice. [5], [6] Allpor (1960) described that personality is management and gathering. Individual and physical elements, which is a unique identification and pattern in the adaptation to the environment Hilgard and Atkinson (1979), declared that a personality is a different form of action, including ways of thinking, will be responsible for defining guidelines for personal adaptation to the environment.

MBTI personality model (Myers-Briggs Type Indicator) is a measure used to classify and describe the personality traits of individuals. Created and developed by Isabel Briggs Myers (1896-1980) and Katharine Cook Briggs (1875-1968)

Carl G. Jung's classification mentioned in the theories of personality type is $8: 1$ ) a global dimension. With a focus on the world outside their own. (Extraverts-E) 2) dimension of looking at the world with a focus on the inner self. (Introverts-I) 3) dimensional perception. Directly from the senses (Sensing-S) 4) recognition that forecasts the future. Or from experience (Intuition-N) 5) dimension of the decision. The main rationale (Thinking-T) 6) The decision by the feeling (Feeling-F) 7) dimension of life. A pattern rule (Judgment-J) 7) lifestyle. Flexibly adapted to the situation. (Perception-P) would be a mix of personality in a different dimension to the personality types, 16 models (16 Type), which is the difference of the attitudes, perceptions, decisions, and way of life is ISTJ. / ISTP / ESTP / ESTJ / ISFJ / ISFP / ESFP / ESFJ / INFJ / INFP / ENFP / ENFJ / INTJ / INTP / ENTP / ENTJ. [7],[8],[9],[10]

\section{METHODOLOGY}

The research methodology applied for this paper is a quantitative method with the following scopes.

A. Objectives

1. To understand the trend of personalities of OHS students during studying at university.

2. To know the tentative requirements of students for a future learning program to meet the OHS professional characteristics.

B. Sampling Method

The total number of samples equal to 50 students who are studying in the Occupational Health and Safety (OHS) 
field with the limitation of time and some specific constraints.

\section{Data Collection}

The questionnaire of 32 questions collected the data and using multiple choice answers 5 Options and attitude in practice the same format using in the previous project.[2] D. Analysis

All data presented in the Descriptive statistics format.

\section{RESULTS}

From data collection and analysis in this survey can be described as shown in Table 1, Fig.1, and Fig.2.

Table 1. Personality test classification types of OHS students

\begin{tabular}{|c|c|c|}
\hline Type & Frequency & Percent \\
\hline ENFJ & 1 & 2 \\
\hline ENFP & 1 & 2 \\
\hline ESFJ & $\mathbf{5}$ & $\mathbf{1 0}$ \\
\hline ESFP & 3 & 6 \\
\hline ENTP & 2 & 4 \\
\hline ESTJ & 1 & 2 \\
\hline INFJ & $\mathbf{6}$ & $\mathbf{1 2}$ \\
\hline INFP & $\mathbf{5}$ & $\mathbf{1 0}$ \\
\hline ISFJ & $\mathbf{1 1}$ & $\mathbf{2 2}$ \\
\hline ISFP & $\mathbf{8}$ & $\mathbf{1 6}$ \\
\hline INTJ & 1 & 2 \\
\hline INTP & 1 & 2 \\
\hline ISTJ & 1 & 2 \\
\hline ISTP & 4 & 8 \\
& & \\
\hline
\end{tabular}

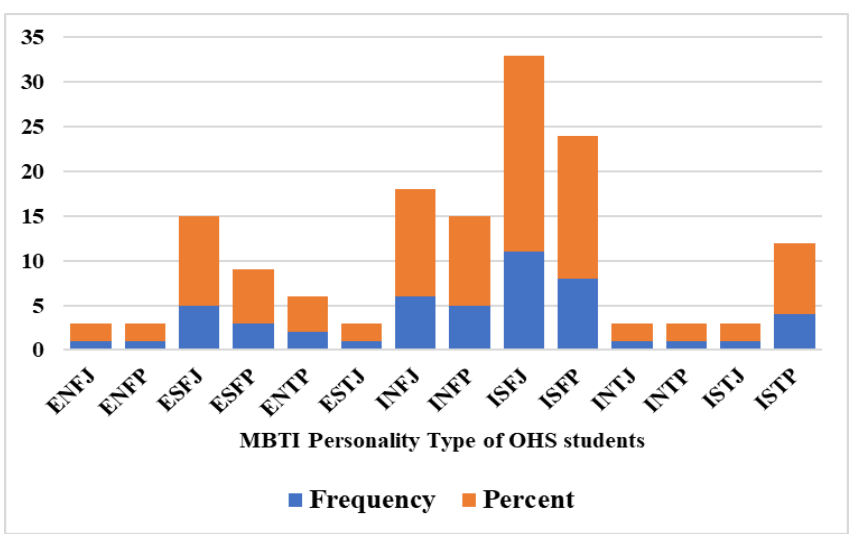

Fig. 1. Personality Frequency/Percentage by Types of OHS students

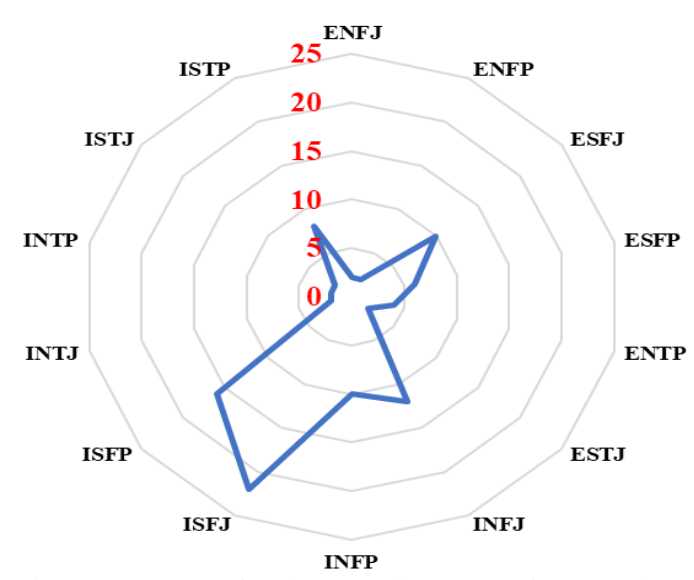

Fig. 2. Percentage of each Personality Types of OHS students
From the Occupational Health and Safety (OHS) professional recommendations, the required skills [11] can be compared with the majors' personality types, as presented in Table 2.

Table 2. The OHS professional requirements compare to the major personality types of OHS students.

\begin{tabular}{|c|c|c|c|c|c|c|}
\hline Required skills of the excellent $\mathrm{OHS}$ professional & $\begin{array}{c}\text { Excellent 0HS } \\
\text { professional } \\
{[11]} \\
\end{array}$ & ISFJ & ISFP & INFJ & INFP & ESFJ \\
\hline \begin{tabular}{|l|} 
Interpersonal skills \\
\end{tabular} & $\bullet$ & $x$ & $x$ & $x$ & $x$ & $\bullet$ \\
\hline Communications skills & $\bullet$ & $x$ & $x$ & $x$ & $x$ & $\bullet$ \\
\hline Leadership & $\bullet$ & $x$ & $x$ & $x$ & $x$ & $\bullet$ \\
\hline Get your priorities right - Recognise safety & $\bullet$ & $\bullet$ & $\bullet$ & $\bullet$ & $\bullet$ & $x$ \\
\hline Humility & $\bullet$ & $\bullet$ & $\bullet$ & $\bullet$ & $\bullet$ & $\bullet$ \\
\hline Broad thinking & $\bullet$ & $x$ & $x$ & $x$ & $x$ & $\bullet$ \\
\hline Remember the Pareto Principle & $\bullet$ & $x$ & $x$ & $\bullet$ & $\bullet$ & $x$ \\
\hline A commitment to a continuous improvement philosophy & $\bullet$ & $\bullet$ & $x$ & $\bullet$ & $\bullet$ & $\bullet$ \\
\hline \begin{tabular}{|l|} 
Change management \\
\end{tabular} & $\bullet$ & $x$ & $\bullet$ & $x$ & $\bullet$ & $x$ \\
\hline OHS technical skills & $\bullet$ & $\bullet$ & $\bullet$ & $\bullet$ & $\bullet$ & $x$ \\
\hline Well developed auditing & $\bullet$ & $\bullet$ & $\bullet$ & $\bullet$ & $\bullet$ & $x$ \\
\hline OHS Project management & $\bullet$ & $\bullet$ & $\bullet$ & $\bullet$ & $\bullet$ & $\bullet$ \\
\hline Learning - Avoid the lecture & $\bullet$ & $\bullet$ & $\bullet$ & $\bullet$ & $\bullet$ & $\bullet$ \\
\hline Team-building skills & $\bullet$ & $x$ & $x$ & $x$ & $x$ & $\bullet$ \\
\hline Sharing & $\bullet$ & $x$ & $x$ & $x$ & $x$ & $\bullet$ \\
\hline Well developed bull-dust detector & $\bullet$ & $\bullet$ & $\bullet$ & $x$ & $x$ & $x$ \\
\hline $\mathrm{X}$ Area need to be der & eloped & & & & & \\
\hline
\end{tabular}

\section{CONCLUSIONS}

1) There is no ENTJ and ESTP personality type from the surveying of $\mathrm{OH} \& \mathrm{~S}$ students.

2) The Personality types of $O H \& S$ students, the possible significant types are ISFJ, ISFP, INFJ, INFP, and ESFJ. Other models are not significantly figuring.

3) The following significant recommendations for $\mathrm{OH} \& \mathrm{~S}$ students who are ISFJ, ISFP, INFJ, INFP. They need the learning program to develop themselves to meet OHS professional requirements in Efficient communication, Leadership, and OHS-Management. However, the ESFJ personality type needs to improve in OHS-Technical and planning.

\section{REFERENCES}

[1] Occupational Safety, Health and Environment Act B.E. 2554, from http://web.krisdika.go.th/data/law/law2/\%a4114/\%a4114-202554-a0001.pdf

[2] Thawut L, Kongsong W, Piyamanotham P, Usahanunth N, Pooworakulchai C, The Personality and Professional Practice Attitude of Civil Engineers in Construction Project in Thailand, International Journal of Engineering Research \& Technology (IJERT)ISSN: 2278-0181 Vol. 8,Issue 06, June-2019,162-165

[3] Thawut L, Kongsong W, Piyamanotham P, Usahanunth N, Development of Personality Test to Be Used With Engineers Working On Construction Project Sites in Thailand, International Journal of Engineering Research and Management (IJERM) Volume-06, Issue-05, May 2019, 16-18

[4] Luangkaew T, Kongsong W, Piyamanotham P, Usahanunth N, The Personality Type of Engineers in Construction Project in Thailand, International Journal of Engineering Research and Management (IJERM) Volume-06, Issue-05, May 2019, 27-30

[5] Myers, K. D., and Kirby, L. 1994. Introduction to type dynamics and development, exploring the next level of type, Consulting Psychologists Press, Inc., Mountain View, Calif.

[6] Myers, I. B., McCaulley, M. H., Quenk, N. L., and Hammer, A. L. 1998. MBTI Manual: A guide to the development and use of 
the Myers-Briggs Type Indicator, Consulting Psychologists Press, Inc., Mountain View, Calif.

[7] O'Brien, T.P., Bernold, L.E. and Akroyd, D. (1998) MyersBriggs Type Indicator and academic achievement in engineering education. International J. of Engineering Education, 14(5), 311315.

[8] Brownsword, A. It Take All Type. New York: Consulting Psychologists Press, Inc., 1998.

[9] Kummerow, J. Talking in Type. New York: Center for Application of Psychological Type, 1985.

[10] M. H. McCaulley, E. S. Godleski, C. F. Yokomoto, L. Harrisberger and E. D. Sloan, Applications of psychological type in engineering education, Engineering Education, 73, 5, (1983) pp. 394-400.

[11] George Robotham(2012),Guidance for the BEGINNING OHS PROFESSIONAL, Australia 